TITLE:

\title{
Dynamical factors affecting ozone mixing ratios in the Antarctic lower stratosphere
}

\section{$\operatorname{AUTHOR}(S)$ :}

Shiotani, Masato; Gille, John C.

\section{CITATION:}

Shiotani, Masato ... [et al]. Dynamical factors affecting ozone mixing ratios in the Antarctic lower stratosphere. Journal of Geophysical Research: Atmospheres 1987, 92(D8): 9811 9824

ISSUE DATE:

1987-08-20

URL:

http://hdl.handle.net/2433/217090

\section{RIGHT:}

(C) 1987 American Geophysical Union. Further reproduction or electronic distribution is not permitted. 


\title{
Dynamical Factors Affecting Ozone Mixing Ratios in the Antarctic Lower Stratosphere
}

\author{
Masato Shiotani ${ }^{1}$ and John C. Gille
}

\author{
National Center for Atmospheric Research, Boulder, Colorado
}

\begin{abstract}
This paper describes the climatology and interannual variability of dynamical quantities and ozone mixing ratios during the southern hemisphere spring. Analyses are made mainly for 6 years, from 1979 to 1984, September through December, using the temperature and geopotential height data provided by the National Meteorological Center (NMC) and the ozone mixing ratio data derived from the solar backscatter ultraviolet (SBUV) instrument on board the Nimbus 7. The seasonal variation of temperature in the southern hemisphere lower stratosphere is rather repeatable, indicating that means over a few years should provide a useful estimate of the climatology. The zonal mean quantities show that the coldest temperatures and zonal winds move poleward and downward from September through November, probably in response to wave forcing. A steep decrease in zonal mean ozone mixing ratios is observed around $60^{\circ} \mathrm{S}$ toward the south pole in September. With time, this high-latitude ozone minimum (or "ozone hole") gets shallower in association with minor warmings and a final warming. Climatological synoptic charts in the lower stratosphere show the circumpolar circulation in the geopotential height field and a prominent planetary wave 1 in the temperature and ozone fields. The phases of the temperature and ozone waves in the lower stratosphere are very similar. The year-to-year variations of the ozone mixing ratio at high latitudes is related to that of the wave activity during the winter and spring. When the wave activity is vigorous, there are weaker westerlies, higher temperatures and higher ozone mixing ratios at high latitudes. The seasonal evolution and the year to year variation appear to be clearly related to wave activity. It is possible that the long term changes in the lower stratosphere are also related to a long-term trend in wave activity, although the evidence is not clear. Because the wave activity in 1979 was very vigorous, a simple comparison of atmospheric states between the 1979 and other recent years could lead to misleading conclusions on the rate of ozone decrease over the Antarctic. A long-term chemical effect is not precluded.
\end{abstract}

\section{INTRODUCTION}

Recently, a remarkable decrease of total ozone has been observed during springtime (September and October) at polar latitudes of the southern hemisphere. Farman et al. [1985] first reported the decrease detected by ground-based observations at Halley Bay $\left(76^{\circ} \mathrm{S}, 27^{\circ} \mathrm{W}\right)$, which have been made since 1957. Prior to this, Chubachi [1984] had pointed out that the total ozone observations at Syowa station $\left(69^{\circ} \mathrm{S}, 40^{\circ} \mathrm{E}\right)$ recorded the lowest values in September and October 1982 since 1966. By using satellite-borne measurements from the solar backscatter ultraviolet (SBUV) instrument and the total ozone mapping spectrometer (TOMS) on board Nimbus 7, Stolarski et al. [1986] have confirmed the decrease of total ozone for seven years from the launch of Nimbus 7 (1978) to the most recent spring data available (1985), and have shown the phenomenon to be of continental size.

The springtime is also an interesting season because of the dynamical evolution of the stratospheric circulation in the southern hemisphere. Unlike the northern hemisphere, southern hemisphere wave activity is vigorous during the spring [Hirota et al., 1983; Shiotani and Hirota, 1985]. Using satellite data, many authors have studied the stratospheric circulation in the southern hemisphere [e.g., Harwood, 1975; Hartmann, 1976; Hartmann et al., 1984; Mechoso et al., 1985]. Although each of their studies dealt with different years, they are in good agreement with each other, and show good repeatability of the circulation from year to year.

However, it appears that no one has investigated the transi-

${ }^{1}$ On leave from Geophysical Institute, Kyoto University, Japan.

Copyright 1987 by the American Geophysical Union.

Paper number 7D0399.

0148-0227/87/007D-0399\$05.00 tion from winter to summer over Antarctica, and its relationship to the seasonal change of the ozone distribution. The aim of this study is to show how this change has taken place over the last few years, and thus to provide a background for a better understanding of the ozone decrease. It is not our purpose to propose a mechanism to explain the recently observed "ozone hole." Because balloon data from the Syowa Station [WMO, 1986; Solomon et al., 1986] show that the largest changes occur near 50 mbar, attention will be centered on the lower stratosphere.

After describing the data used in this study in section 2 , we present some of the climatological features of the dynamical and ozone regimes in the southern hemisphere (sections 3 and 4) and their interannual variability (section 5). The implications for ozone change are discussed in section 6.

\section{Data and Method of ANalysis}

The temperature and geopotential height data used in this study are made up of the global tropospheric data for levels from 1000 to 100 mbar from the National Meteorological Center (NMC) of the U.S. National Oceanic and Atmospheric Administration (NOAA) and global stratospheric data for levels from 70 to 0.4 mbar from the NOAA Climate Analysis Center. (Hereafter, we simply refer to this data set as the NMC data set.) The NMC data were interpolated to $5^{\circ}$ latitude circles, then Fourier transformed to provide a zonal mean and coefficients for 6 longitudinal waves. The NMC data are available on the following 18 pressure levels: 1000 , $850,700,500,400,300,250,200,150,100,70,50,30,10,5,2,1$ and 0.4 mbar.

The ozone data were obtained from the SBUV instrument on board the Nimbus 7 spacecraft. These were obtained as profiles and total column amounts of ozone from the National Space Science Data Center. The profiles give mixing ratios at 
9 levels: $100,70,50,30,10,5,2,1$ and 0.4 mbar. The profile data were then interpolated to $5^{\circ}$ latitude circles for latitudes $\leq 80^{\circ}$ and mapped using a Kalman filter estimation procedure [Rodgers, 1977; Kohri, 1981] to yield a zonal mean and coefficients for 6 longitudinal waves.

The backscattered radiances provide little direct indication of the ozone mixing ratios below $10 \mathrm{mbar}$, in part because of the complicating effects of multiple scattering. In the archival ozone profiles, information at these levels is obtained from the observed total ozone, the column amount above 10 mbar, and regression relationships based on ozone distribution observed by balloon-borne instrument. While this procedure provides plausible values under conditions which are similar to those for which the statistics were developed, they can result in highly improbable values in the Antarctic spring [McPeters et al., 1986]. For these reasons we have used the ozonesonde data from the Syowa station to develop regression equations to estimate the high latitude $\left(\geq 60^{\circ} \mathrm{S}\right)$ ozone mixing ratios at levels from 30 to $100 \mathrm{mbar}$, using SBUV total ozone and 10-mbar mixing ratios, and NMC temperatures as predictors.

Figure 1 shows line plots of the estimated SBUV data interpolated to the same latitude-longitude location as Syowa station, compared to the ozone observations at Syowa (marked by $S)$ at 30 and 50 mbar from September to December 1982. The corrected SBUV data are in reasonable agreement with the Syowa observations. There is similar agreement at 70 and 100 mbar. There is also good agreement on individual profiles. The SBUV 10-mbar data agree well with the Syowa soundings. In November and December the Syowa observations show large variations, because it is a season of the circulation reversal, when the ozone field might be spatially very variable.

To estimate the wind field we used balanced winds instead of geostrophic winds. Robinson [1986] pointed out that the momentum flux and its divergence calculated from the geostrophic wind field is overestimated in his numerical model, especially at high latitudes, because the geostrophic wind neglects local curvature effects. He proposed the use of balanced winds, which can be calculated easily from the geopotential height field. Compared with calculations from geostrophic winds, the momentum flux and its divergence calculated from the balanced winds are reduced, and are in good agreement with those calculated for his system described by the primitive equations. Moreover, using geopotential height and temperature data sets derived from satellite observations, Randel [1987] showed that the use of the geostrophic wind overestimates the momentum flux and its divergence compared with the use of balanced winds.

In the calculation of balanced winds $\left(u^{\prime}, v^{\prime}\right)$ for each wave number, we found that the equations can have a singularity at low latitudes and that this singular point moves poleward as the zonal wave number increases. Because of this singularity and the dominance of planetary waves in the stratosphere, we used balanced winds only for wave numbers 1 and 2 at high and middle latitudes (poleward of $30^{\circ} \mathrm{S}$ ); for wave numbers 1 and 2 at low latitudes and for wave numbers 3-6 at all latitudes, we used the geostrophic wind approximation. As a zonal mean of the wind field we used the mean zonal gradient wind.

\section{Zonal Mean Climatology}

The seasonal evolution of the stratospheric circulation is much more repeatable in the southern than in the northern hemisphere. Figure 2 shows the annual march of the zonal mean temperature at $80^{\circ}$ and 50 mbar for the northern and southern hemispheres over nearly 7 years. From summer to winter the seasonal marches of the two hemispheres are repeatable. From winter to summer, however, these are different between the two hemispheres. In the northern hemisphere, temporal variations of the zonal mean temperature are highly variable because major warmings occur there. On the other hand, in the southern hemisphere the seasonal marches are repeatable, although there are small variations associated with minor warmings. Consequently, temperatures during the winter and spring time in the southern hemisphere are much colder than in the northern hemisphere. Because the interannual variability is rather limited, annual averages over the
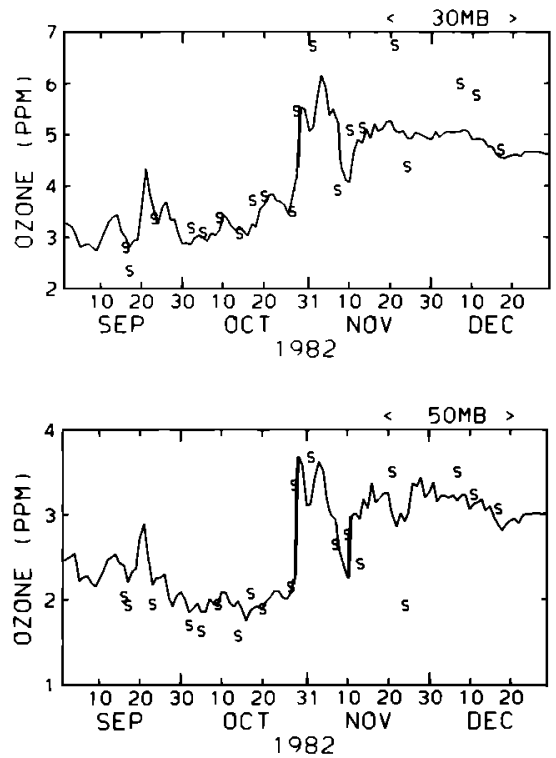

Fig. 1. Line plots of the estimated SBUV ozone data interpolated to the same latitude-longitude point as Syowa station, and ozone observations at Syowa (marked by $S$ ) from September to December 1982 for (a) 30 mbar and (b) 50 mbar.
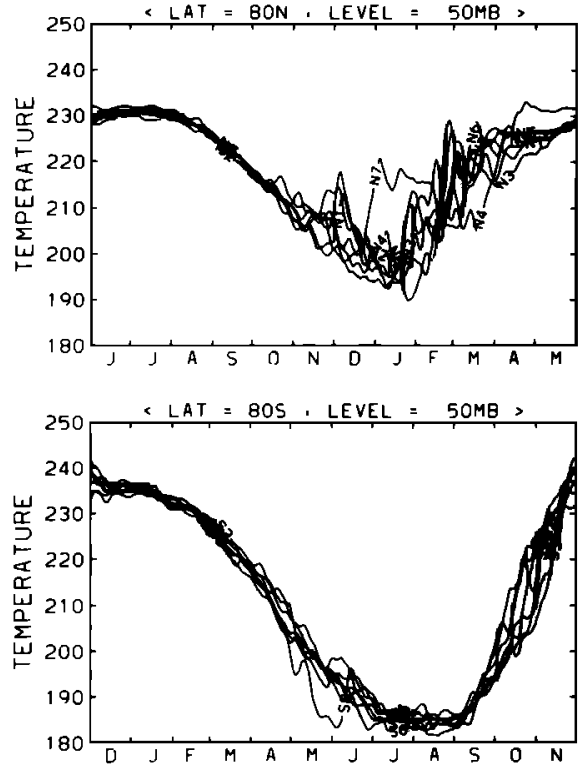

Fig. 2. Annual marches of the zonal mean temperature for about 6.7 years from October 1978 to July 1985 at 50 mbar for $(a) 80^{\circ} \mathrm{N}$ and (b) $80^{\circ} \mathrm{S}$. 

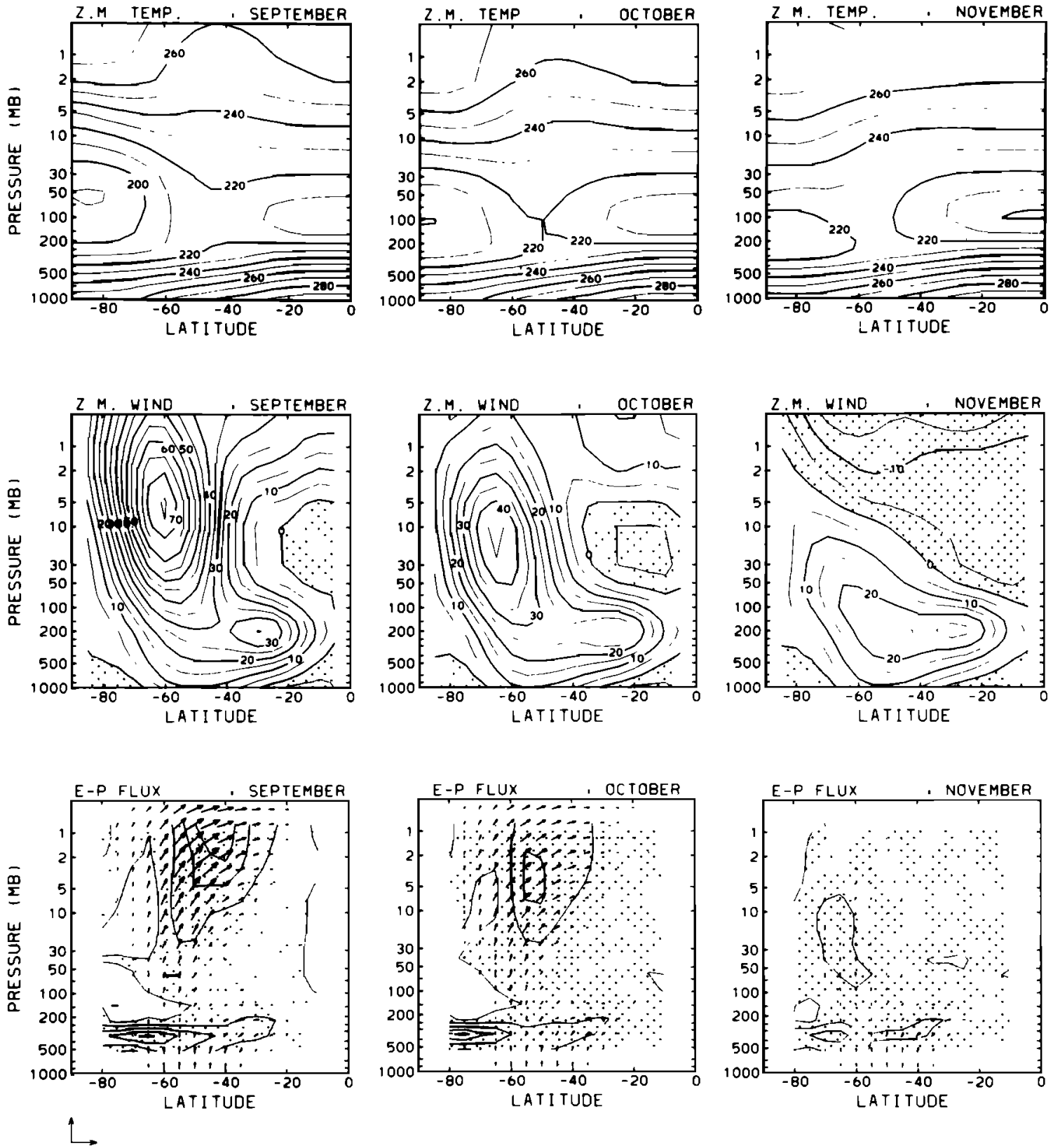

Fig. 3. Climatological latitude-height sections of (a) the zonal mean temperature (contour interval $10 \mathrm{~K})$, (b) the mean zonal gradient wind (contour interval $5 \mathrm{~m} \mathrm{~s}^{-1}$ ) and $(c)$ the E-P flux and wave driving $D_{F}$ (contour interval $2.5 \times 10^{5} \mathrm{~m}$ $\mathrm{s}^{-2}$ ). Negative values are shaded. Reference arrow for the E-P flux shows $1.0 \times 10^{9} \mathrm{~kg} \mathrm{~s}^{-2}$ for horizontal direction and $1.0 \times 10^{9} / c(c=182) \mathrm{kg} \mathrm{s}^{-2}$ for vertical direction. (See text for the scaling.)

5-year period 1979-1983 for which SBUV data are now available should be representative of the long-term average.

First we describe the climatological monthly mean of the zonal mean temperature, the mean zonal gradient wind, the Eliassen-Palm (E-P) flux and its divergence for the three months of September, October and November, averaged over the 1979-1983 period. Our results for September are comparable to those of Mechoso et al. [1985] which showed the climatology in the southern hemisphere from June to September averaged over 4 years from 1979 to 1982 .

Figure $3 a$ shows latitude-height sections of the zonal mean temperature for the three months. In September there exist cold temperatures $(<190 \mathrm{~K})$ at high latitudes in the lower stratosphere; this region is colder in the earlier months [Me- choso et al., 1985]. Referring to the climatology in the northern hemisphere by Geller et al. [1983] or Figure 2, even in midwinter the minimum temperature at high latitudes is 198 $\mathrm{K}$, emphasizing the different roles of planetary waves in the two hemispheres. As Mechoso et al. [1985] mentioned, there are two baroclinic zones in the upper and lower stratosphere. In particular, a reversal of the latitudinal gradient in the zonal mean temperature is a prominent feature in the upper stratosphere during the spring time [e.g., Labitzke and Barnett, 1973; Barnett, 1974; Hirota et al., 1983]; these features in the zonal mean temperature are related to the mean zonal wind through the thermal wind relationship. In October the cold core at high latitudes warms and moves downward. In November the cold core still exists and moves downward to 200 
mbar (from 50 mbar in September). The temperature gradients in the upper and lower stratosphere become smaller as the month progresses. The downward movement of the cold core continues until December at $\mathbf{3 0 0}$ mbar. We will show this feature in more detail later.

Figure $3 b$ shows cross sections of the mean zonal gradient wind. The mean zonal gradient wind is weaker than the mean zonal geostrophic wind because the mean zonal gradient wind takes into account the centrifugal force. In September the speed of maximum westerlies is about $75 \mathrm{~m} \mathrm{~s}^{-1}$ at $60^{\circ} \mathrm{S}$ and 5 mbar. By October the stratospheric jet has weakened; at the same time, the tropospheric jet has also weakened. The stratospheric jet moves downward and slightly poleward. In November, when it is in the final warming stage, the stratospheric jet seems to be merged into the tropospheric jet. The transition of the mean zonal wind from September to November is gradual, but it is affected by minor warmings. We will see the interannual variability of the seasonal march of the mean zonal wind later.

Figure $3 c$ shows cross sections of the E-P flux $F$ and wave driving $D_{F}$ defined as [e.g., Edmon et al., 1980a, b; Dunkerton et al., 1981]

$$
\mathbf{F}=[F(\theta), F(z)]
$$

where

$$
F(\theta)=-\rho_{0}(z) a \cos \theta \overline{u^{\prime} v^{\prime}}
$$

and

$$
\begin{gathered}
F(z)=+\rho_{0}(z) a \cos \theta\left(\frac{f}{N^{2}}\right) \overline{v^{\prime} \Phi_{z}^{\prime}} \\
D_{F}=\frac{1}{\rho_{0}(z) a \cos \theta} \nabla \cdot \mathbf{F}
\end{gathered}
$$

where

$$
\nabla \cdot \mathbf{F}=\frac{1}{a \cos \theta} \frac{\partial(F(\theta) \cos \theta)}{\partial \theta}+\frac{\partial F(z)}{\partial z}
$$

The notation is based on Holton [1975]. In plotting the E-P flux in the vertical cross section we applied the graphical convention as described by Baldwin et al. [1985]; we have multiplied $F$ by the factor $\exp (z / H)$. Figure $3 c$ was calculated from the 5-year monthly average of daily values, not from the 5 -year monthly mean field.

In September the wave activity in the upper and middle stratosphere is the most vigorous of the 3 months. Since $M e$ choso et al. [1985] showed that the wave activity in September is most vigorous of the 4 months from June to September, September is the most active month of the year. There are two large convergence regions of the wave driving $D_{F}$; at midlatitudes in the upper stratosphere, and at high- and midlatitudes in the upper troposphere. Although the averaging period is different between our study and Mechoso et al. [1985], values of the convergence zone in the upper stratosphere are similar. However, the positive $D_{F}$ in the highlatitude middle stratosphere is much smaller than that calculated by Mechoso et al. [1985]. This result is consistent with the results of Robinson [1986], who showed that the momentum flux and its divergence at high latitudes is overestimated by using the geostrophic wind field. In October the wave activity is weaker but still vigorous. The region of the large
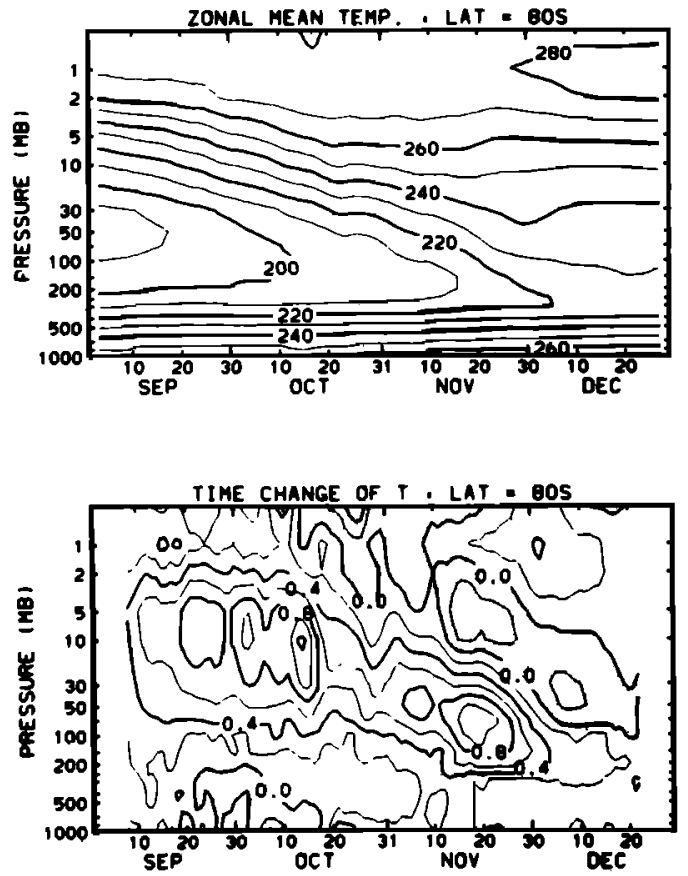

Fig. 4. Climatological time-height sections of (a) the zonal mean temperature (contour interval $10 \mathrm{~K}$ ) and $(b)$ rate of change of temperature (contour interval $0.2 \mathrm{~K} \mathrm{~d}^{-1}$ ) at $80^{\circ} \mathrm{S}$ from September to December. Negative values are shaded.

negative $D_{F}$ in the stratosphere moves downward and poleward. Although in November the wave activity is low, a slight convergence zone in the stratosphere moves further downward and poleward.

We show the downward movement of the minimum temperatures and the maximum westerlies more clearly in the 5-year mean time-height sections (Figures 4 and 5). A 5-day running mean was applied to most figures of time-height and time-latitude sections in this paper, with the exception that a 15-day running mean was used for Figures $4 b$ and $5 b$. At $80^{\circ} \mathrm{S}$ the minimum temperatures move downward from $50 \mathrm{mbar}$ in early September to 300 mbar in early December (Figure 4a) while becoming warmer. (A similar feature was reported by Farrara and Mechoso [1986] for the 6-year mean temperature.) The time change of the zonal mean temperatures (Figure $4 b$ ) shows that the maximum temperature change also moves downward from $5 \mathrm{mbar}$ in early September to 200 mbar in early December. According to the monthly mean climatology by Mechoso et al. [1985], the maximum temperature tendency moves from 1 mbar in June to 5-10 mbar in September. Thus in the southern hemisphere the maximum temperature tendency comes from the upper stratosphere in June and moves downward to the lower stratosphere in early December.

The maximum westerlies (near $60^{\circ} \mathrm{S}$ ) also move downward from 5 mbar in early September to 200 mbar in November (Figure 5a). Harwood [1975] reported similar downward movement of the maximum westerlies. The acceleration of the mean zonal wind (Figure $5 b$ ) shows the maximum deceleration moves downward from the upper stratosphere in September to the lower stratosphere in early December. Because the E-P flux and its divergence are sporadic, a similar cross section of their 5-year mean does not show such a regular evolution as Figures $4 a$ and $5 a$. 

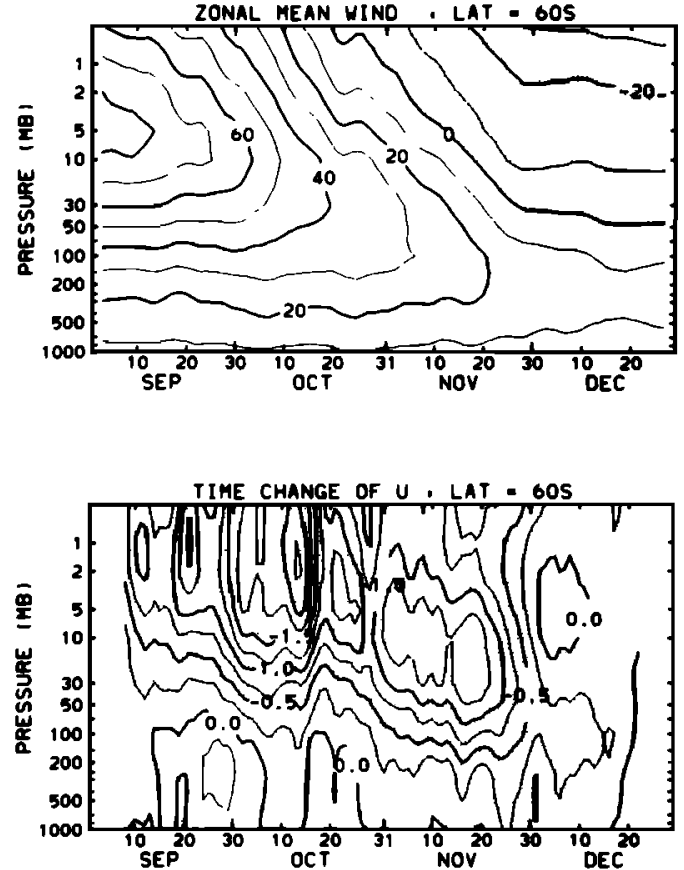

Fig. 5. As Figure 4 but for (a) the mean zonal gradient wind (contour interval $10 \mathrm{~m} \mathrm{~s}^{-1}$ ) and (b) wind acceleration (contour interval $0.25 \mathrm{~m} \mathrm{~s}^{-1} \mathrm{~d}^{-1}$ ) at $60^{\circ} \mathrm{S}$.

The downward motion of wave driving $D_{F}$ in Figure $3 c$ suggests that the region of large wave damping moves downward as the region of weak westerlies (or a critical line) moves downward. The downward motion of the cooling region just above the heating band in Figure $4 b$ also suggests a dynamical effect. As predicted by Matsuno [1971], the temperature change caused by planetary waves incident on a critical level is positive below the critical level and negative above it at high latitudes. The positive feedback of the downward motion is reminiscent of the mechanistic model of the quasi-biennial oscillation.

We turn next to the climatology of the zonal mean ozone mixing ratio and the ozone transport by horizontal eddies. Figure $6 a$ shows latitude-height sections of the zonal mean ozone mixing ratio for the 3 months from September to November averaged over the 5 years of 1979-1983. In September there are maxima in both the upper and lower stratosphere at mid latitudes. Particularly, in the lower stratosphere there exists a steep drop of the ozone mixing ratio toward the pole, a so-called ozone hole. In October the ozone mixing ratio at high latitudes in the middle stratosphere increases. (See, for example, the $6 \mathrm{ppm}$ contour line.) In the lower stratosphere there is also an increase of ozone at high latitudes, and the ozone hole is gradually filled. By November the hole at high latitudes in the lower stratosphere has almost disappeared.

Figure $6 b$ shows the ozone transport by the horizontal eddies, $\overline{v^{\prime} \mathrm{O}_{3}{ }^{\prime}} . W u$ et al. [1985] reported that large contributions to the ozone transport are due to mean vertical advection and horizontal eddy processes during the northern hemisphere winter, based on SBUV ozone data. For the 3 months, the basic configurations of the horizontal eddy transport are similar; negative maxima are located at high latitudes in the middle stratosphere. In September a negative maximum of about $-4.0 \mathrm{ppm} \mathrm{m} \mathrm{s}{ }^{-1}$ is located at $55^{\circ} \mathrm{S}$ and $10 \mathrm{mbar}$. Paired with the negative maximum is a positive maximum at $50^{\circ} \mathrm{S}$ in the upper stratosphere. The zero line tilts downward toward the equator. These features are similar to the results by $\mathrm{Wu}$ et al. [1985], although the level of the negative maximum is located higher (5 mbar) in their results than in ours (10 mbar). In October the positive maximum in the upper stratosphere is reduced, but the negative maximum in the mid stratosphere is enhanced with a value of about $-6 \mathrm{ppm} \mathrm{m} \mathrm{s}^{-1}$. The position of the negative maximum moves poleward to $60^{\circ}-65^{\circ} \mathrm{S}$. In November both positive and negative maxima are reduced and the position of the negative maximum moves farther pole-
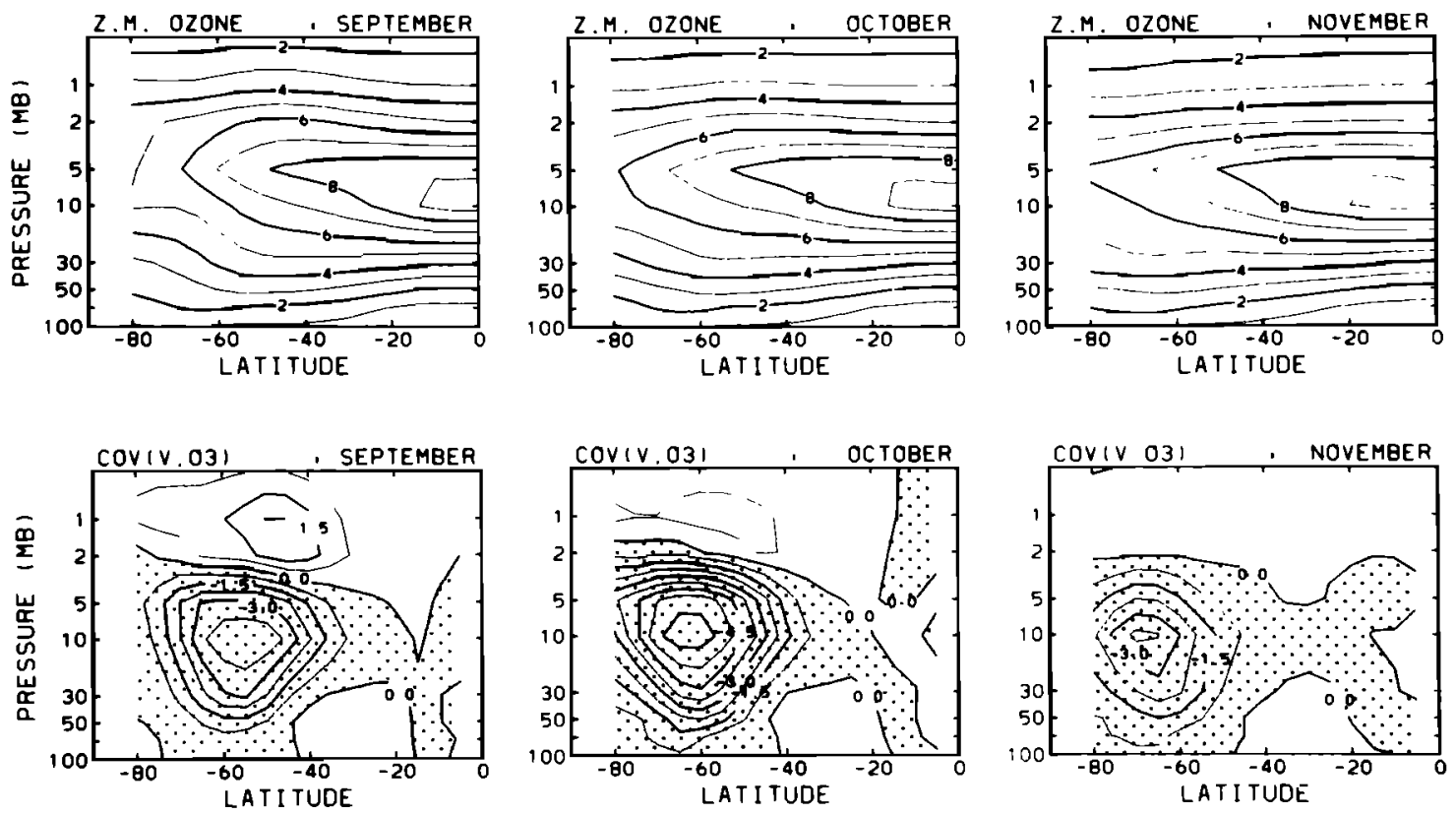

Fig. 6. As Figure 3 but for (a) the zonal mean ozone mixing ratio (contour interval $1 \mathrm{ppm}$ ) and $(b)$ the ozone transport of the horizontal eddy (contour interval $0.75 \mathrm{ppm} \mathrm{m} \mathrm{s}^{-1}$ ). 

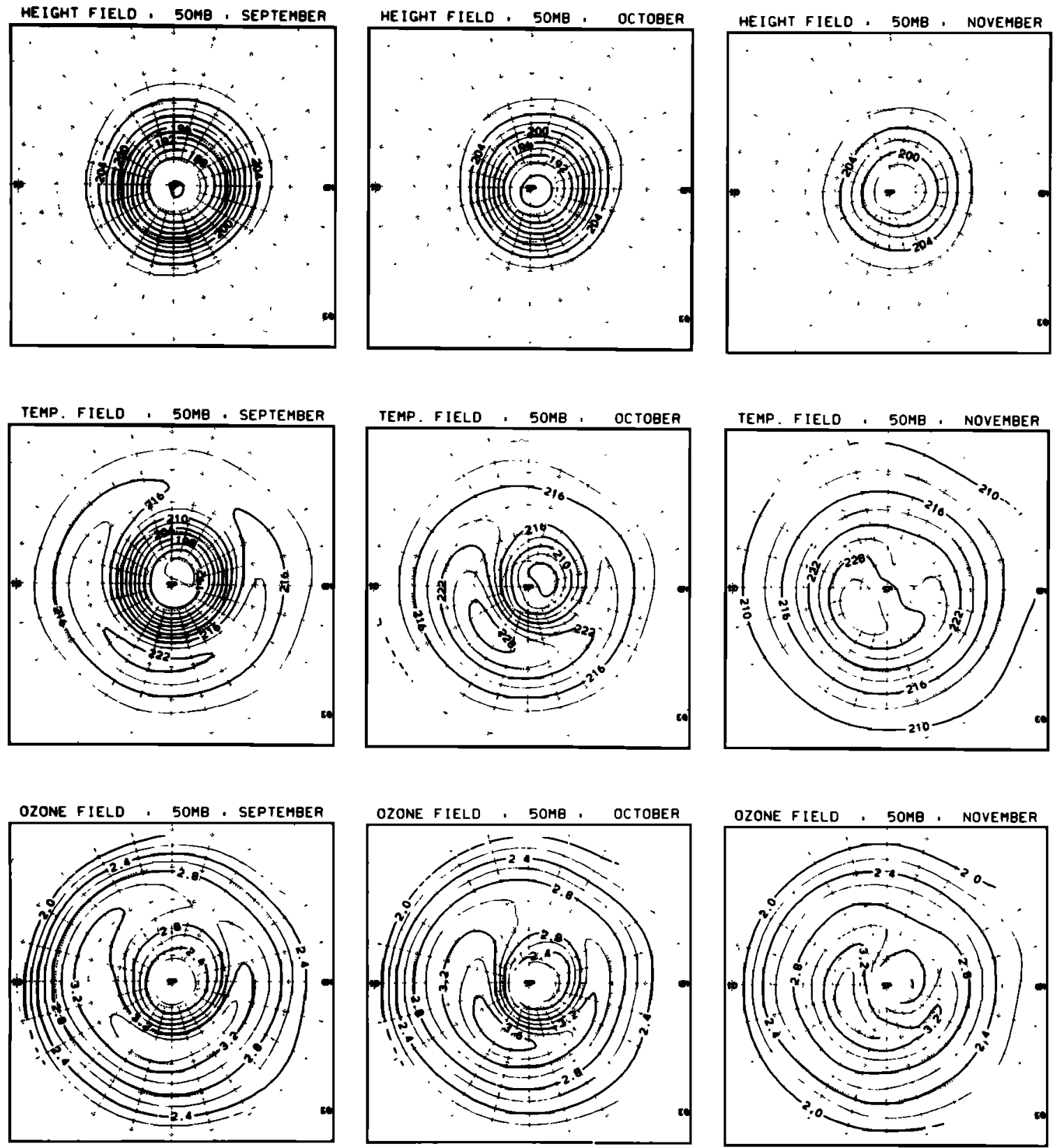

Fig. 7. Climatological synoptic charts projected on a stereographic grid (poleward from $15^{\circ} \mathrm{S}$ is shown) of (a) the geopotential height field (contour interval $200 \mathrm{~m}$ ), (b) the temperature field (contour interval $3 \mathrm{~K}$ ) and $(c)$ the ozone mixing ratio field (contour interval $0.2 \mathrm{ppm}$ ) at $50 \mathrm{mbar}$ in September, October and November.

ward at $70^{\circ} \mathrm{S}$. This poleward movement may be related to the reduction of the ozone hole as we will see below.

\section{Synoptic Climatology}

In the southern hemisphere the monthly mean fields, e.g., the temperature or ozone fields, are also repeatable; wave structure of these time mean fields is almost the same for each year. (See monthly mean total ozone charts for 7 years from 1979 to 1985 by Stolarski et al. [1986].) We show the 5-year average monthly mean field of the geopotential height, temperature and ozone mixing ratio at $\mathbf{5 0}$ mbar for the 3 months of September, October and November. The $50 \mathrm{mb}$ level is a representative one for considering dynamical effects on total ozone, since the largest contribution to the total ozone occurs in the lower stratosphere. Our climatological charts of the geopotential height and temperature fields agree well with those by Knittel [1976] for the 5-year mean from 1968 to 1972.

Figure $7 a$ shows the geopotential height field projected on a polar stereographic grid. The height field for the 3 months appears to be circular compared with the climatology during the northern hemisphere winter. In September, as might be expected from Figure $3 b$, a steep slope of the vortex is located near $60^{\circ} \mathrm{S}$. In October the vortex is still stable and strong. In fact, there are appreciable wave amplitudes (see Figure 10) which are masked by the steep slope. By November, the vortex is weak and shallow; however, at this level the circulation is still cyclonic.

The temperature field (Figure $7 b$ ) in September and October 

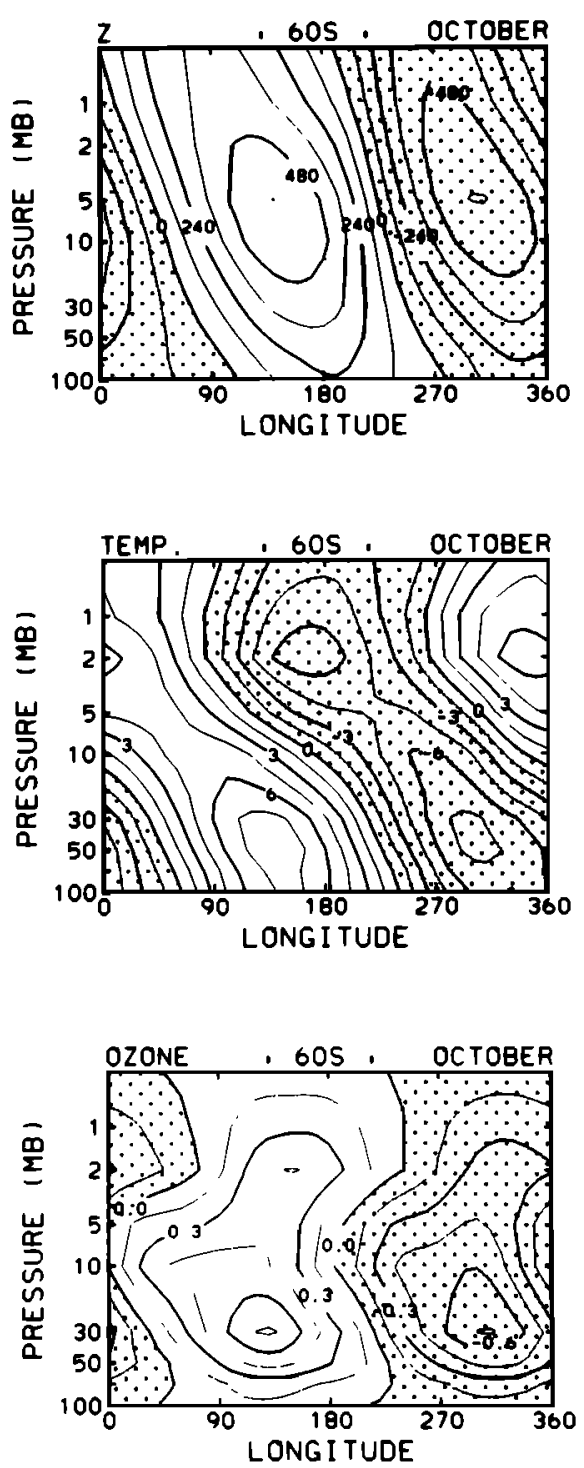

Fig. 8. Climatological longitude-height sections of deviation from a zonal mean for (a) the geopotential height wave (contour interval $120 \mathrm{~m}),(b)$ the temperature wave (contour interval $1.5 \mathrm{~K}$ ) and $(c)$ the ozone mixing ratio wave (contour interval $0.15 \mathrm{ppm}$ ) at $60^{\circ} \mathrm{S}$ in $\mathrm{Oc}$ tober. Negative values are shaded.

is decidedly noncircular. A cold core is located over the polar region, with a warm band at mid-latitudes having a horse shoe shape (wave number 1). In the southern hemisphere planetary wave 2 is also prominent; however, in the time mean field it is not detectable because of its eastward traveling nature [Harwood, 1975; Hartmann, 1976]. In September the coldest temperature is $188 \mathrm{~K}$ near the pole, and the warmest temperature is $223 \mathrm{~K}$ at mid-latitudes, while the climatology by Knittel [1976] shows the coldest temperature $187.8 \mathrm{~K}$ and the warmest temperature $225.6 \mathrm{~K}$. The longitude of maximum temperatures between the two climatologies is somewhat different ; our result shows the maximum around $105^{\circ} \mathrm{E}$, while Knittel's [1976] is around $150^{\circ} \mathrm{E}$. In October the core of cold temperatures is still strong with the coldest temperature of 202 $\mathrm{K}$ (Knittel, $203.1 \mathrm{~K}$ ). The high-temperature band with a maximum of $229 \mathrm{~K}$ moves poleward and rotates clockwise (eastward). The longitude of maximum temperatures is still differ- ent between our climatology and Knittel [1976]; however, the rotational direction and movement are similar to each other. In November, low temperatures are replaced by high temperatures around the polar region.

The ozone field at $\mathbf{5 0}$ mbar (Figure 7c) is closely related to the temperature field. In September there exists a deep ozone hole over the polar region and a high ozone band at midlatitudes with a horse shoe shape. Although the high-ozone band lies slightly inside the high-temperature band, the phase of the two is almost the same. In October there still exists the deep ozone hole over the polar region. As we see in the temperature field (Figure $7 b$ ), the high ozone band also moves poleward and eastward. Stolarski et al. [1986] showed a similar phase of wave number 1 in the total ozone averaged over October for 7 years from 1979 to 1985, based on the TOMS observations. Hence the horse shoe shape of the ozone and temperature fields in September and October is a repeatable and prominent feature in the southern hemisphere. In November the hole almost disappears, but there is a weak pair of low- and high-ozone regions over Antarctica.

The good correspondence between the horse shoe shaped temperature and ozone fields suggests that at mid-latitude there exists downward motion that brings down high ozone with the adiabatic heating there, and that at the polar region there exists upward motion that brings up low ozone with the adiabatic cooling there. Tung et al. [1986] suggested the existence of such a reversed circulation to understand the Antarctic ozone hole. To confirm this hypothesis more extensive work on the net radiative heating and the residual mean circulation is needed.

We briefly mention the vertical structure of the geopotential height field, the temperature field and the ozone field. Figure 8 shows longitude-height sections of the deviations from a zonal mean for the three quantities in October averaged over the 5 years at $60^{\circ} \mathrm{S}\left(60^{\circ} \mathrm{S}\right.$ is chosen because it is near the latitude of maximum amplitude; results at higher latitudes are similar). Height waves (Figure $8 a$ ) have maximum amplitudes of wave number 1 at 5 mbar and tilt westward. Temperature waves have a westward tilt and two amplitude maxima for wave number 1 in the lower and upper stratosphere; there is a nodal point around 5 mbar. On the other hand, ozone waves tilt westward in the lower stratosphere and eastward in the upper stratosphere. In the upper stratosphere the ozone waves are out of phase with the temperature waves (Figure $8 b$ and $8 c$ ), which is expected in a region where ozone is photochemically controlled (see also Gille et al. [1980]). In the lower stratosphere Hartmann and Garcia [1979] showed with a simple mechanistic model that the ozone waves are in phase with the height waves where the ozone distribution is dynamically controlled and horizontal eddy advection is dominant. The departure suggests that other effects may be significant. However, our results show a strong correspondence with the temperature waves in the lower stratosphere.

\section{INTERANNUAL VARIABILITY}

Although the interannual variability of the stratospheric circulation is much smaller in the southern hemisphere than in the northern hemisphere (e.g., Figure 2 and Geller et al. [1984]), it is variable during the spring time. Moreover, recent ozone observations have shown a remarkable decrease of the total ozone over the southern polar region in October. In this section we will see the interannual variability of the dynamical 

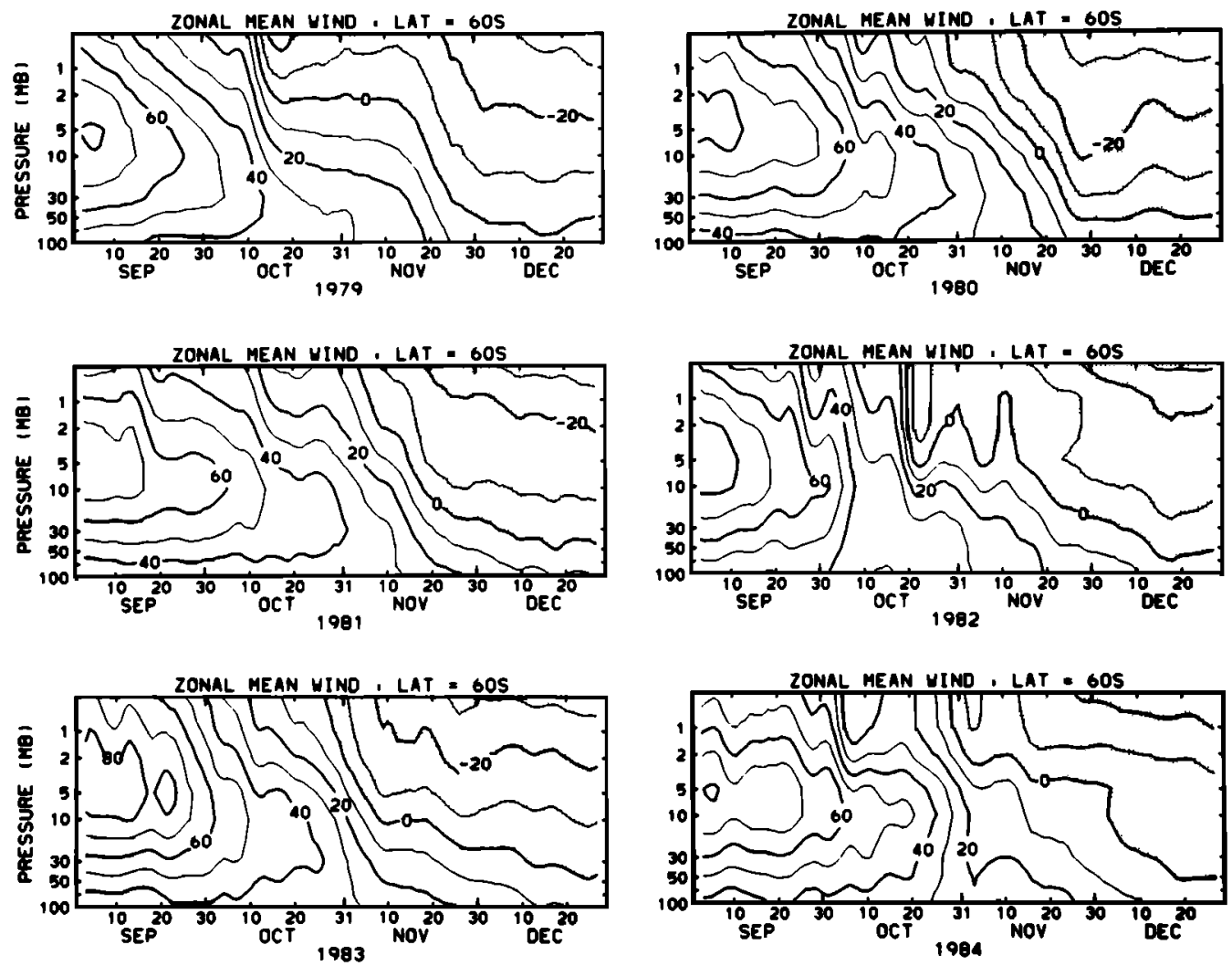

Fig. 9. Time-height sections of the mean zonal gradient wind (contour interval $10 \mathrm{~m} \mathrm{~s}^{-1}$ ) at $60^{\circ} \mathrm{S}$ from September to December for the 6 years of $1979-1984$. Negative values are shaded.

quantities and ozone distributions during the spring time in the southern hemisphere.

Figure 9 shows time-height sections of the mean zonal gradient wind in the stratosphere $(100-0.4 \mathrm{mbar})$ at $60^{\circ} \mathrm{S}$ fo 6 years from 1979 to 1984 . For each of the 6 years the downward movement of the maximum westerlies is clear, as was seen in Figure 5. However, the seasonal evolution of the mean zonal wind is variable in October and November. In 1979 a minor warming occurred in mid October and the wind speed suddenly decreased. (This warming is reported by Yamazaki and Mechoso [1985].) After this event the wind speed in the stratosphere was highly stable for about a month, until a final warming in late November brought the easterlies down to the lower stratosphere. In 1980 the wind speed decreased slightly around October 10 in conjunction with a minor warming; however, it was not as effectively reduced as in 1979. The downward motion of the zero line was gradual from late October $(0.4 \mathrm{mbar})$ to late November (30 mbar). Thus the strong westerlies (for example, see the $40 \mathrm{~m} \mathrm{~s}^{-1}$ contour line) remain until the end of October. The seasonal evolution of the mean zonal wind in 1981 is similar to that in 1980 ; there is no sudden decrease in the wind speed, and the movement of the zero line is gradual. In 1982, in contrast, the seasonal evolution was similar to that in 1979 ; in mid-October there was a minor warming that rapidly decreased the wind speed, followed by a gradual reduction. Consequently, the wind speed in the mid and lower stratosphere was weaker in 1982 than 1980 and 1981. In 1983 the seasonal evolution of the zonal wind was similar to that in 1980 and 1981 . The seasonal evolution in 1984 was slightly different from other years; a minor warming in early October decelerated the wind speed suf- ficiently in the upper stratosphere, but there remained strong westerlies in the middle and lower stratosphere. The times of changing circulation from westerlies to easterlies for the 6 years seem to be getting later in the lower stratosphere. Note that for these months the flow remains generally westerly at 70 mbar and usually so at 50 mbar. However, in October, when the ozone decrease has been observed, there is no clear trend of the wind speed. Rather, the times of minor warmings affect the wind speed in October. The character of the zonal wind transition at $80^{\circ} \mathrm{S}$ (not shown) is rather different, although 1979 is similar to $60^{\circ} \mathrm{S}$ with the final change about November 20. In the following 5 years easterlies descend suddenly to 70 mbar; the approximate dates for these transitions are November 25, December 21, December 8, November 26 and December 12 , possibly suggesting a tendency to be somewhat later.

Figure 10 shows time-latitude sections of the total amplitude $A_{0}$ for the height wave at 50 mbar for the 6 years. $A_{0}$ is defined as

$$
A_{0}=\left\{\sum_{k=1}^{6}\left(a_{k}^{2}+b_{k}^{2}\right)\right\}^{1 / 2}
$$

where $a_{k}$ and $b_{k}$ are the cosine and sine coefficients for the wave number $k$. Although Figure $7 a$ shows a nearly circular height field, the wave amplitudes are fairly large, but are obscured by the steep slope of the strong vortex. As we see in the climatology of the temperature field (Figure $7 b$ ), the maximum amplitudes of the height wave also slowly moves poleward from around $55^{\circ} \mathrm{S}$ at the beginning of September to around $65^{\circ} \mathrm{S}$ in November. The contribution to the total wave amplitude $A_{0}$ is mainly from wave numbers 1 and 2 ; generally, the 

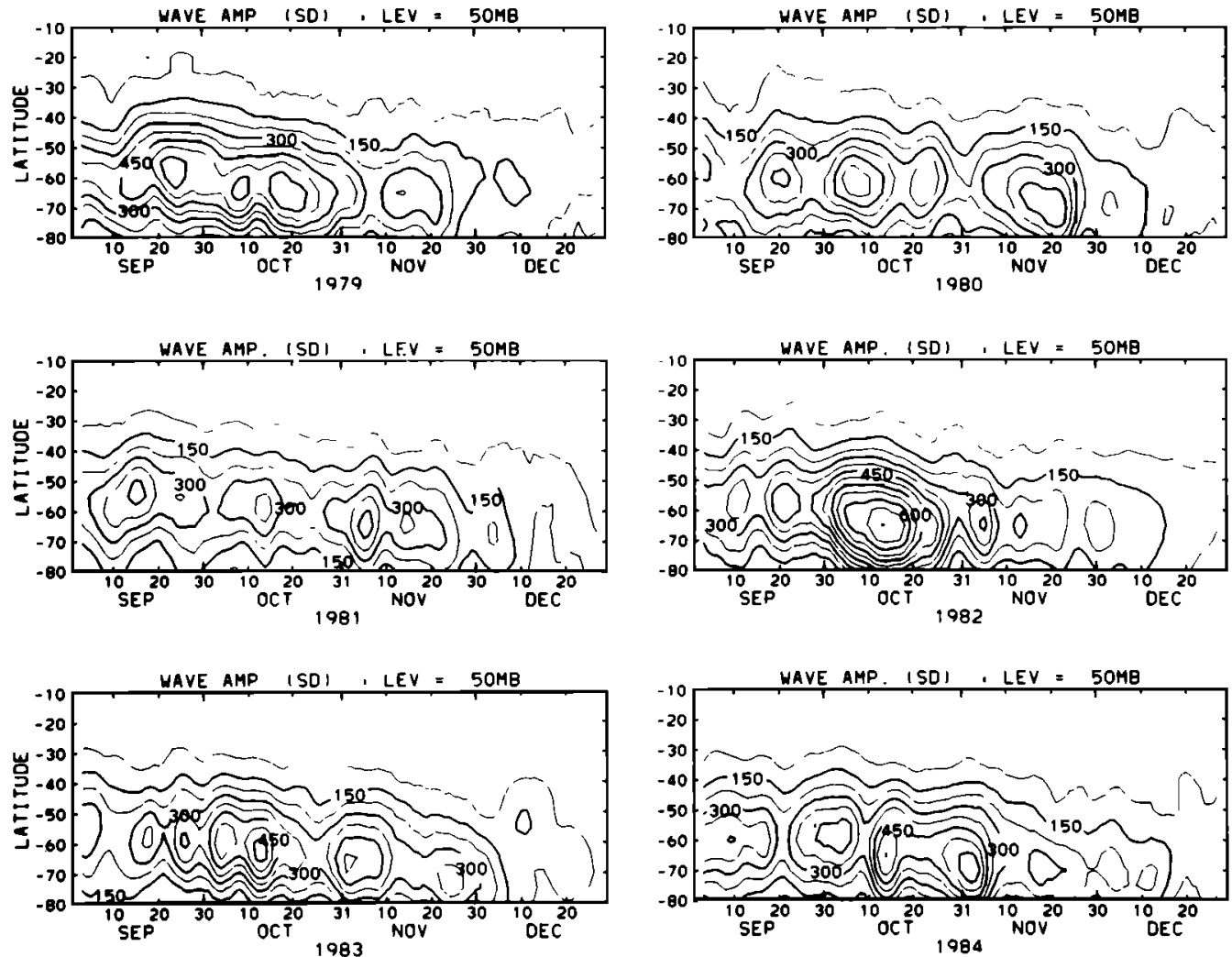

Fig. 10. Time-latitude sections of the total amplitude of the height wave (contour interval $75 \mathrm{~m}$ ) at 50 mbar from September to December for the 6 years of 1979-1984.

total is almost all due to wave 1 . The difference of seasonal evolution between the 2 years (1979 and 1982) and other years is clear. In October of 1979 and 1982 there is a big wave event following the sudden decrease of the mean zonal wind (Figure
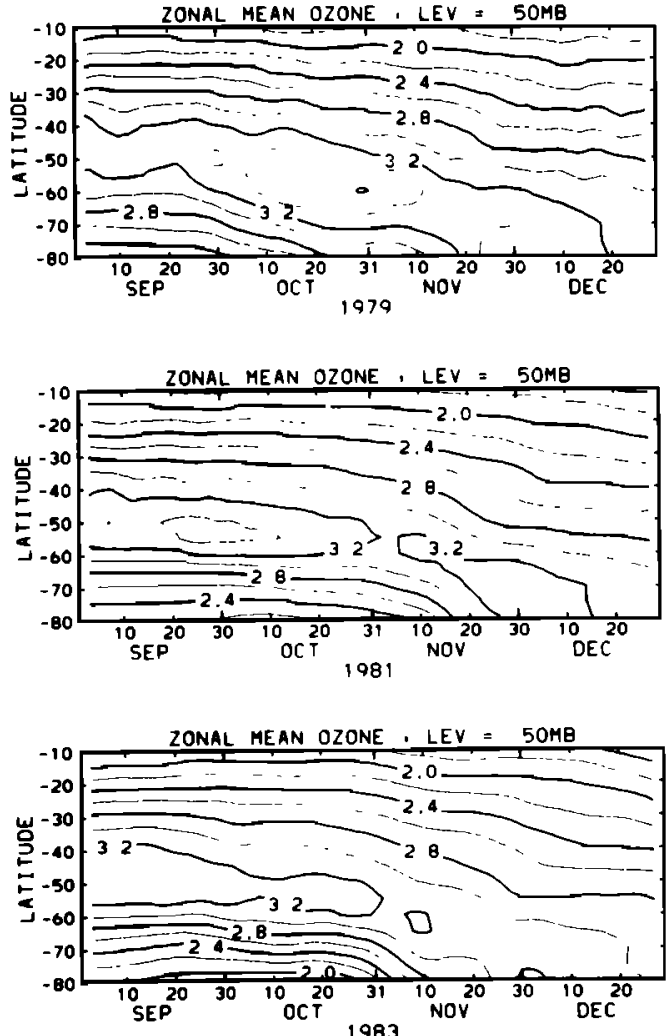

9). The wave amplitudes in the other years are smaller than in 1979 and 1982.

Figure 11 shows time-latitude sections of the zonal mean ozone mixing ratio at 50 mbar for the 6 years. In 1984 the
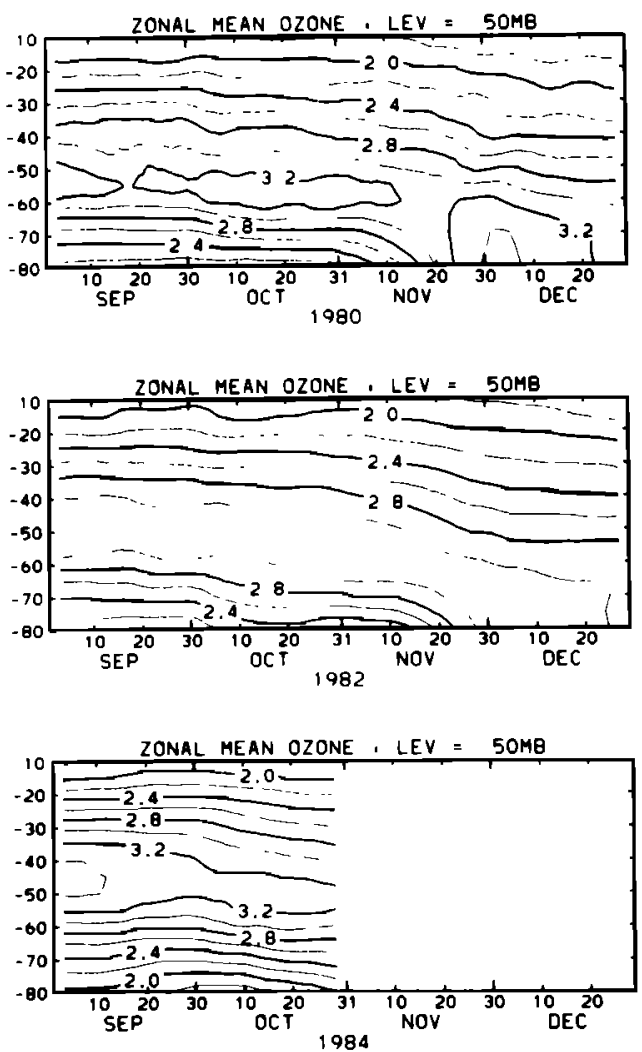

Fig. 11. As Figure 10 but for the zonal mean mixing ratio (contour interval $0.2 \mathrm{ppm}$ ). (In 1984 only September and October are shown.) 

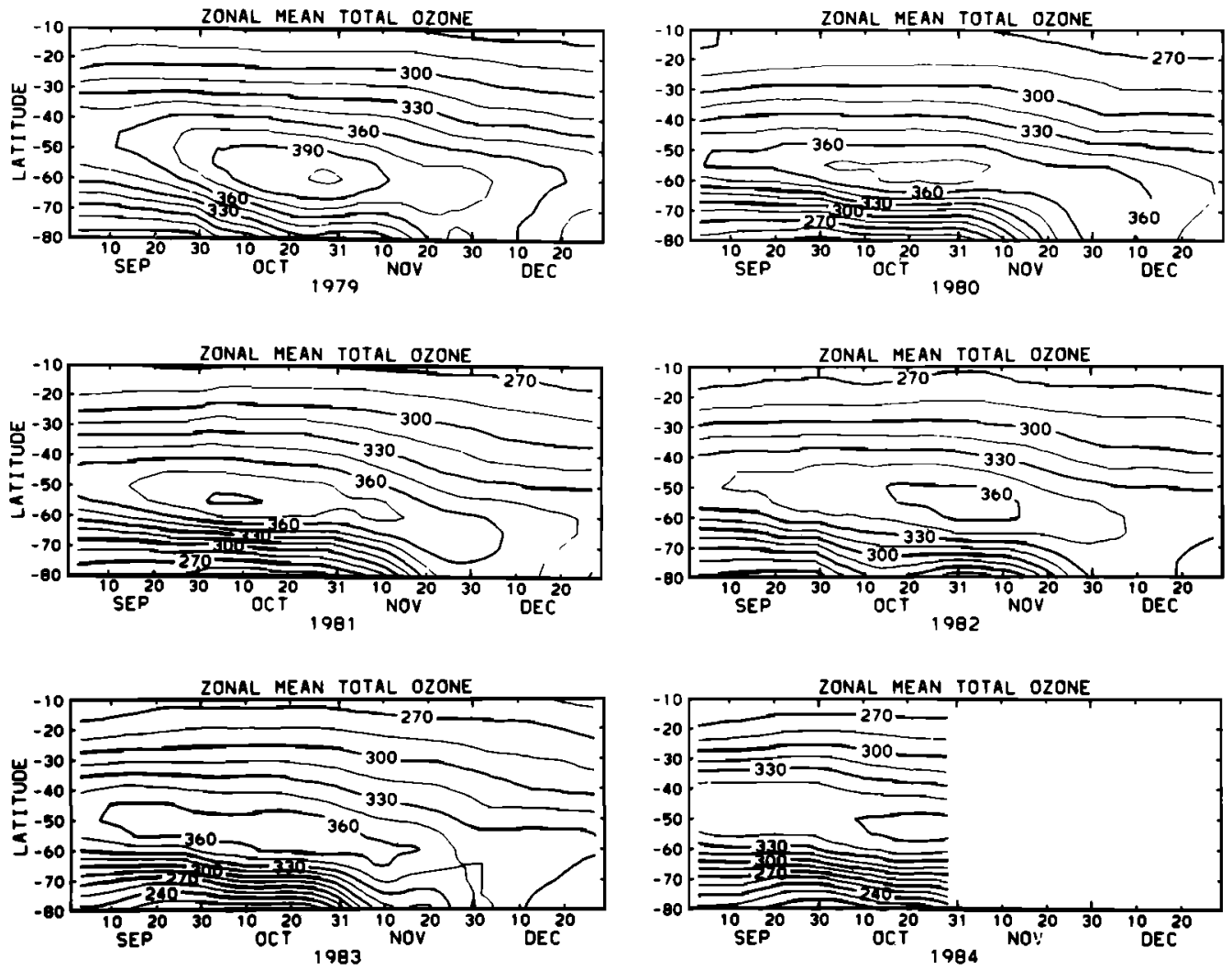

Fig. 12. As Figure 10 but for the zonal mean total ozone (contour interval 15 DU). (In 1984 only September and October are shown.)

data are presently available only in September and October. For each of the 6 years the ozone maximum, which is around $50^{\circ} \mathrm{S}$ at the beginning of September, slowly moves poleward, reaching polar latitudes in late November or December. In
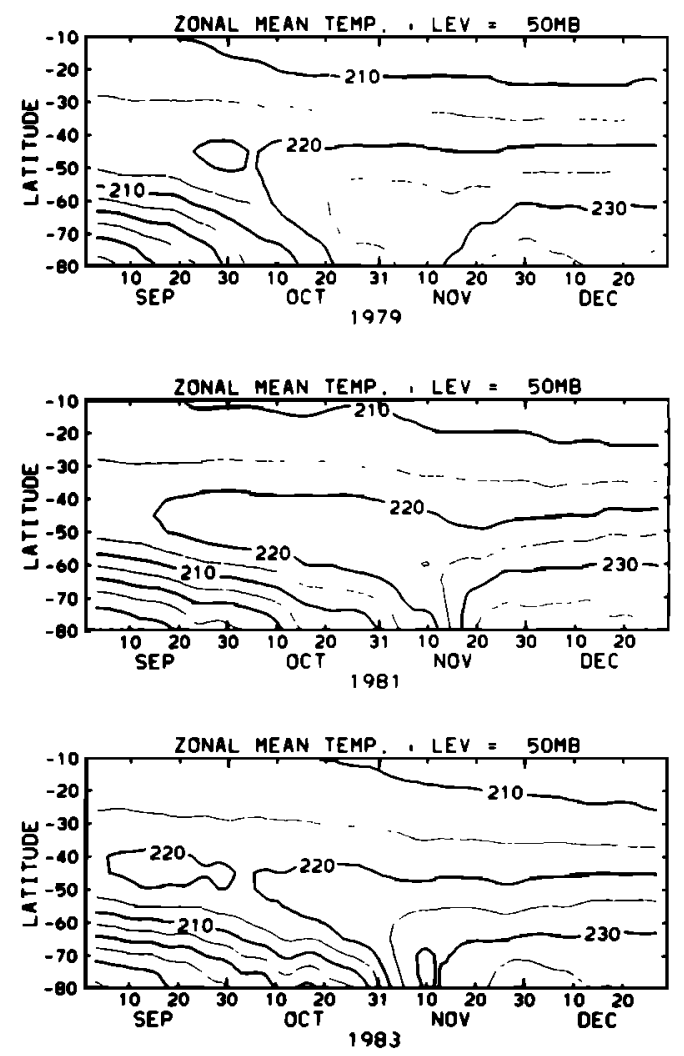

1979 the maximum value is $3.6 \mathrm{ppm}$ at $60^{\circ} \mathrm{S}$ in late October and the minimum value is $2.2 \mathrm{ppm}$ at $80^{\circ} \mathrm{S}$ in early September. In 1980 the maximum value is reduced to $3.2 \mathrm{ppm}$ at $55^{\circ} \mathrm{S}$ in early October and $3.5 \mathrm{ppm}$ at $80^{\circ} \mathrm{S}$ in early December. The
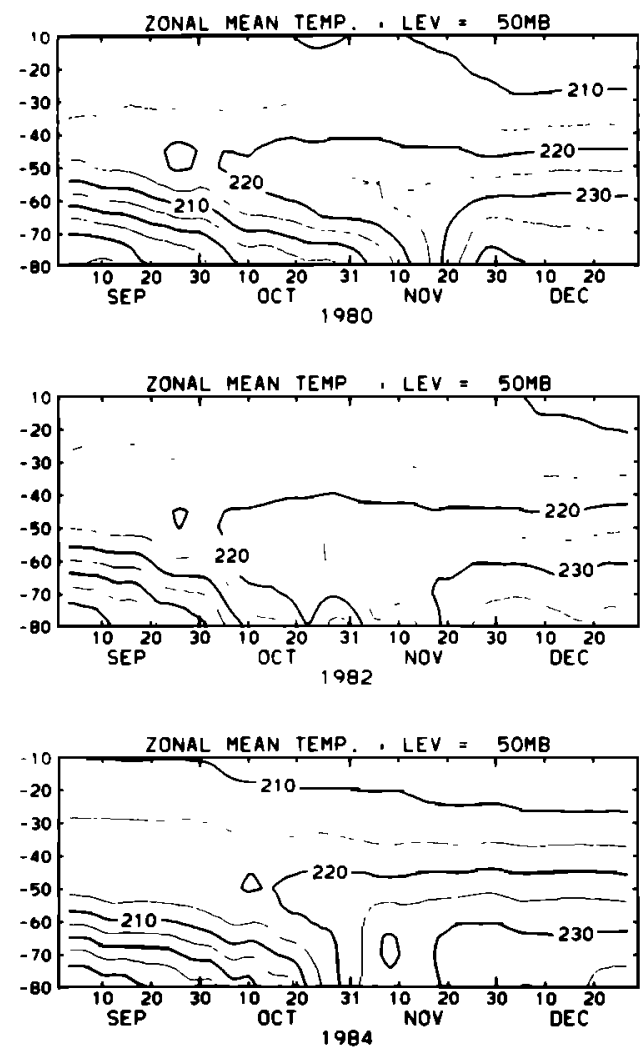

Fig. 13. As Figure 10 but for the zonal mean temperature (contour interval $5 \mathrm{~K}$ ). 

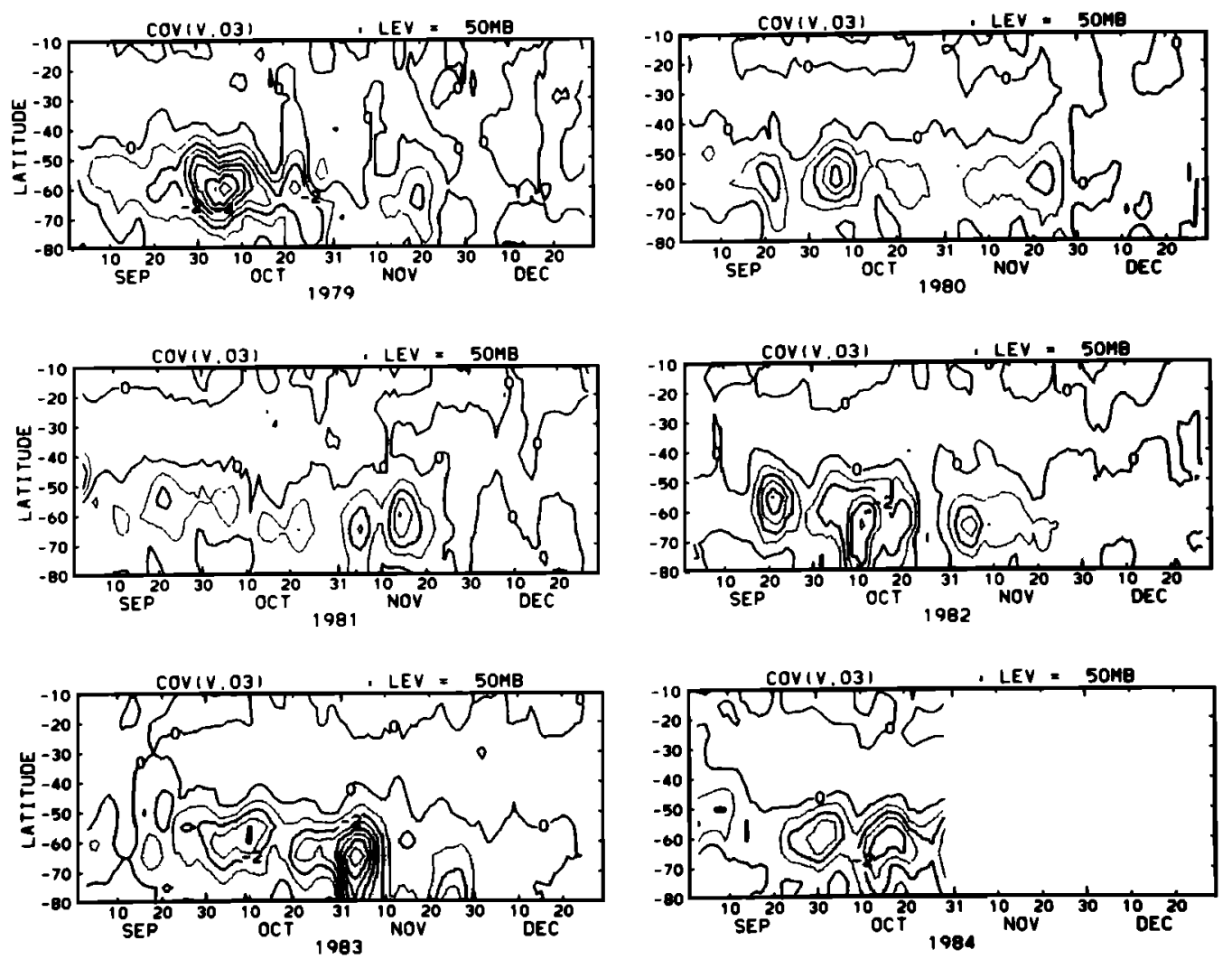

Fig. 14. As Figure 10 but for the ozone transport of the horizontal eddy, $\overline{v^{\prime} O_{3}{ }^{\prime}}$ (contour interval $1 \mathrm{ppm} \mathrm{m} \mathrm{s}{ }^{-1}$ ). Negative values are shaded.

minimum value is also reduced to $2.1 \mathrm{ppm}$ at $80^{\circ} \mathrm{S}$ in the middle of October. The low ozone mixing ratio at high latitudes continues longer in 1980 than in 1979. In 1981 the maximum value again increases to $3.5 \mathrm{ppm}$ at mid-latitudes in late September, but the minimum value is almost the same $(2.1$ ppm) as that in 1980. In 1982 the maximum value is reduced again (the $3.2 \mathrm{ppm}$ contour line disappears) and the minimum value is $2.2 \mathrm{ppm}$ in late September. In mid-October the ozone mixing ratio at high latitudes increases, associated with a minor warming. In 1983, the $3.2 \mathrm{ppm}$ contour line appears again, and the minimum value decreases to $1.8 \mathrm{ppm}$ at $80^{\circ} \mathrm{S}$ in mid-October. In 1984, although our plot is limited to September and October, the maximum value is $3.5 \mathrm{ppm}$ at $45^{\circ} \mathrm{S}$ in early September and the minimum value is $1.7 \mathrm{ppm}$ in early October.

The seasonal evolution of the zonal mean ozone mixing ratio at $\mathbf{5 0}$ mbar is repeatable; however, there are some variations in maximum values at mid latitudes and minimum values at polar latitudes. The minimum values of the zonal mean ozone mixing ratio at $\mathbf{5 0}$ mbar, inferred from the SBUV data, decrease by $26 \%$ in September and October from 1979 to 1984 , similar to the decrease of the total ozone at polar latitudes reported by Farman et al. [1985] and Stolarski et al. [1986]. On the other hand, for the maximum values at mid latitudes, there is no clear decreasing or increasing trend.

A time-latitude presentation of the SBUV zonal mean total ozone (Figure 12) shows many of the same features. At the beginning of September there are low values of $80^{\circ} \mathrm{S}$ and high values at $50^{\circ} \mathrm{S}$. The maximum moves toward the pole, slowly until mid-November, then very rapidly. There is usually a mid-latitude maximum in October, corresponding to a mini- mum at high latitude, suggesting some latitudinal redistribution of the total ozone. However, in several years, the deepest high-latitude minimum occurs earlier than the mid-latitude maximum. The high-latitude minimum was 270 DU (1 Dobson unit is $1 \mathrm{matm} \mathrm{cm}$ ) in 1979, but below 210 in 1984, for a $22 \%$ decrease. The mid-latitude maximum, over $405 \mathrm{DU}$ in 1979 , has also decreased irregularly to about 365 DU over this period for a $10 \%$ decrease. In addition, the 360 DU contour no longer reaches high latitudes.

Figure 13 shows time-latitude sections of the zonal mean temperature at $50 \mathrm{mb}$ for the 6 years. The ridge of the maximum temperatures corresponds to that of the maximum ozone mixing ratio at the same level (Figure 11), although the latitudes of the maximum ozone mixing ratio or total ozone are located a little poleward of the maximum temperature (see Figures $7 b, 7 c$ ). Figure 13 illustrates the relationship between the seasonal marches of cold temperatures at high latitudes and the zonal mean wind. As shown in Figure 9, for the years 1979 and 1982 there are minor warmings that bring easterlies in the upper stratosphere at $60^{\circ} \mathrm{S}$. If we look at cold temperatures at high latitudes (for example, see the $210 \mathrm{~K}$ contour line) in 1979 and 1982 , the $210 \mathrm{~K}$ contour line reaches $80^{\circ} \mathrm{S}$ around October 10, while in 1980, 1981, and 1983 it reaches $80^{\circ} \mathrm{S}$ around November 1 , and in 1984 around October 20. For the zonal mean temperatures a simple trend of the cold temperatures at high latitudes is not clear, although the temperature data observed at ground based stations show a fairly simple trend [cf. Sekiguchi, 1986; Angell, 1986]. Thus, our result shows that the year-to-year variations of the cold temperatures are affected by wave events related to minor warmings. 

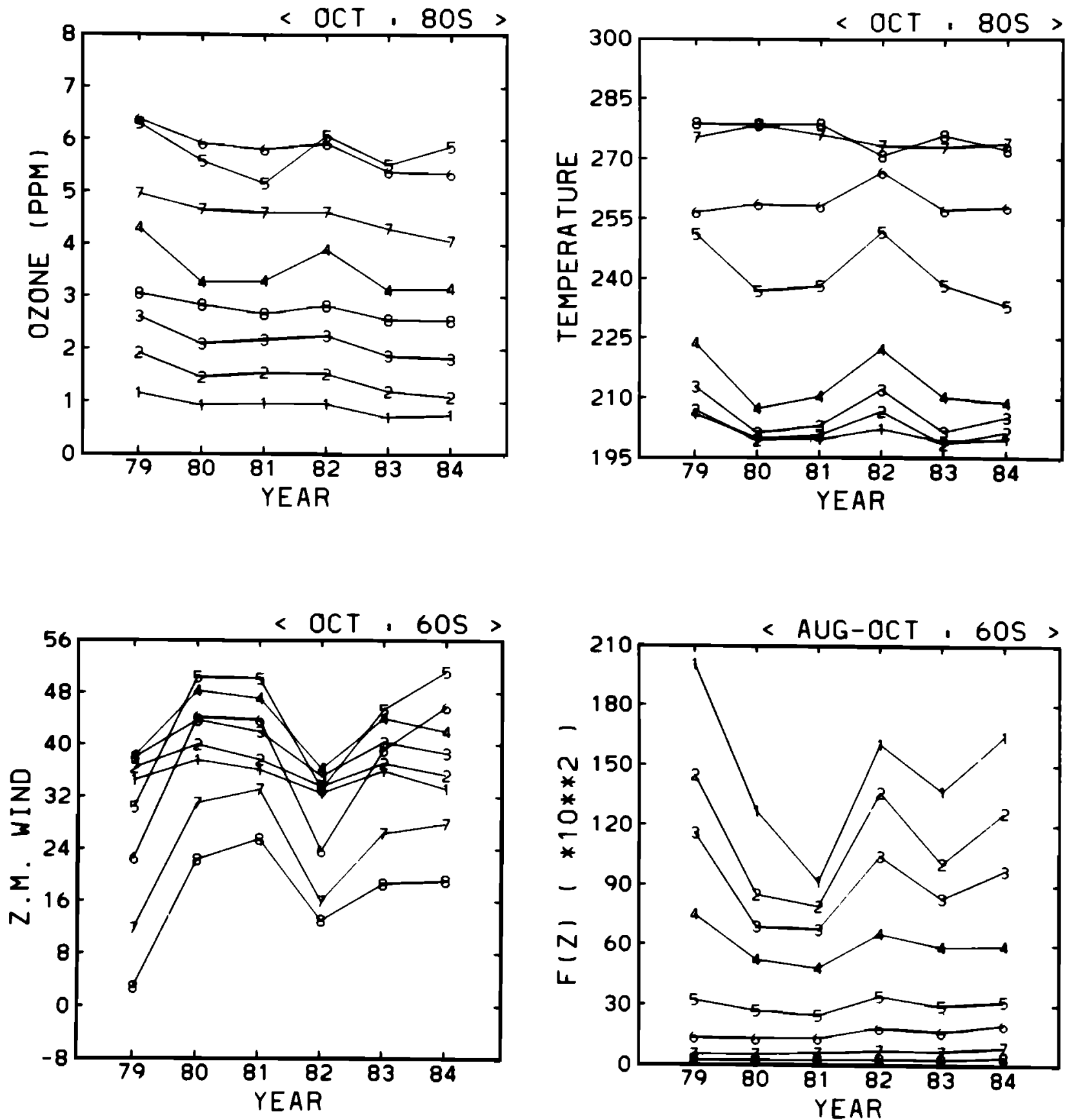

Fig. 15. Year-to-year variations of (a) the zonal mean ozone mixing ratio (unit $\mathrm{ppm}$ ) at $80^{\circ} \mathrm{S}$ averaged over October, (b) the zonal mean temperature (unit $\mathrm{K}$ ) at $80^{\circ} \mathrm{S}$ averaged over October, (c) the mean zonal gradient wind (unit $\mathrm{m} \mathrm{s}^{-1}$ ) at $60^{\circ} \mathrm{S}$ averaged over October and $(d)$ the vertical component of the E-P flux (unit $10^{2} \mathrm{~kg} \mathrm{~s}^{-2}$ ) at $60^{\circ} \mathrm{S}$ averaged over August to October. Marks of $i(i=1-8)$ correspond to the pressure levels in the following order: 100, 70, 50, 30, 10, 5, 2, 1 mbar.

Figure 14 shows time-latitude sections of the horizontal ozone transport $\overline{v^{\prime} \mathrm{O}_{3}^{\prime}}$ at $50 \mathrm{mbar}$ for the 6 years. As we see in the climatology of Figure $6 b$, there are negative (southward) regions at high latitudes, positive regions at around $20^{\circ}-40^{\circ} \mathrm{S}$, and again small negative regions at equatorial latitudes. The variation of negative values at high latitudes is related to wave events. The large ozone transport associated with wave events is sporadic, and the times of the active periods are different for each year. While wave 1 height and ozone are considerably larger than wave 2 , the mean transports by the two wave components are comparable, although one or the other may dominate in a particular event. Big wave events in October 1979, 1982 and 1984 caused minor warmings that sufficiently changed wind speeds in the upper stratosphere, while in September and October 1980, 1981 and 1983 wave activity is small corresponding to the strong mean zonal wind. Thus Figure 14 does not show a simple trend of the horizontal ozone transport, $\overline{v^{\prime} \mathrm{O}_{3}^{\prime}}$.

Finally, we will summarize the interannual variability of the dynamical quantities and ozone distributions by paying special attention to the month of October when the ozone decrease has been observed. Initial results of the interannual 
variability of the dynamical quantities are reported by Newman and Schoeberl [1986] and Newman [1986]. Figure $15 a$ shows year-to-year variations of the zonal mean ozone mixing ratio at $80^{\circ} \mathrm{S}$. The SBUV observations indicate a decreasing trend of the ozone mixing ratio in the whole stratosphere. Caution must be exercised in drawing a strong conclusion about a decrease in the ozone mixing ratio profiles because a systematic drift in the SBUV instrument may be at least partially responsible for the trend. Rather, we should pay attention to the high ozone mixing ratio in 1979 and 1982, which was observed especially in the middle stratosphere $(30$ and 10 mbar). As Figures 9-14 show, the seasonal marches of the dynamical quantities and ozone distributions are closely related to each other. The year-to-year variations of the zonal mean temperature (Figure 15b) are similar to those of Figure $15 a$ with high temperatures in 1979 and 1982 in the lower and middle stratosphere. Note that the compressed scale underemphasizes significant changes, which can reach $15 \mathrm{~K}$ in the middle stratosphere. The mean zonal wind speed at $60^{\circ} \mathrm{S}$ (Figure 15c) shows a close relation to these two. As we might expect from the dynamical relationships, colder temperatures at high latitudes are related to the strong westerlies. Moreover, these are related to the wave activity. Figure $15 d$ shows the year-to-year variation of the vertical component of the E-P flux, which is a measure of the vertical propagation of planetary waves. Wave driving $D_{F}$ shows similar interannual variability to Figure $15 a$. Because the effect of wave activity should be considered to be cumulative, we chose an averaging period from August to October. It is evident that warmer temperatures, weaker westerlies and high ozone are associated with more vigorous wave activity. The ozone decrease in these years is probably true. However, if the year 1979 was the most active of the 6 years, these data by themselves may not be sufficient to demonstrate that there is a long-term trend.

\section{Conclusions}

We have investigated the climatology and interannual variability of dynamical factors and their effects on the ozone mixing ratio during the southern hemisphere spring. We have paid special attention to the Antarctic lower stratosphere where the decrease of the total ozone has been observed recently. Because the stratospheric circulation in the southern hemisphere is highly repeatable, it is reasonable to look at the seasonal change of a multiyear average as a first step.

Data have been presented on the seasonal evolution of the zonal mean circulation and ozone fields in the southern hemisphere lower stratosphere from late winter to late spring. Mechanistically, the data are consistent with the following picture. The wave driving $D_{F}$ is (negatively) large in middle latitudes of the upper stratosphere in September. As the zonal westerlies are decelerated, the wind structure is altered such that the maximum values are displaced downward and poleward as well as being reduced. As the zero wind line descends, the region of strong wave driving $D_{F}$ moves poleward and downward as the season progresses. The downward motions associated with the deceleration produce an adiabatic warming in the lower stratosphere, first at mid-latitudes, but increasingly poleward as time goes by. Additionally, these motions bring ozone-rich air down to the lower stratosphere, so that the warm regions have higher ozone mixing ratios, and the high ozone region moves toward the pole with time as the warm region does. Thus it appears that the changes are due to the seasonal changes in the wave-mean flow interaction, indicated by the wave driving.

In the synoptic description of the climatological field, the geopotential height field is almost circumpolar. On the other hand, in the temperature and ozone fields planetary wave number 1 (with a horse shoe shape) is prominent in the lower stratosphere; moreover, these two fields are in good positive correlation. The generation of the planetary wave 1 must be affected by the Antarctic continent whose shape has a strong wave number 1 component. Orographic effects or surface temperature contrast are two possible mechanism, but there may also be an effect of the surface albedo distribution.

Concerning interannual variability, the zonal mean ozone mixing ratio, the zonal mean temperature, the mean zonal gradient wind and the wave activity are related to each other. When there is vigorous winter/spring wave activity (1979 and 1982), the mean zonal wind is weaker, the zonal mean temperature is warmer and the zonal mean ozone is richer at high latitudes than those in a quiet winter/spring. Clearly, the zonal mean ozone at high latitudes is affected by the wave activity. This interannual variability of the ozone and temperature values and the EP flux support the general picture presented above. These data support the hypothesis advanced by Mahlman and Fels [1986].

This mechanism of itself does not explain the presence or growth of the ozone minimum seen at high latitudes at the end of each winter. This might be due to an upward motion at high latitude, as suggested by Tung et al. [1986]. Our preliminary calculations of the residual circulation do not support this for 1979 , but one would expect that stronger wave activity, such as characterized that year, would drive stronger downward motions at high latitudes, tending to overcome an upward motion. Weaker wave motions, on the other hand, would not drive as strong downward motions, and high latitudes would be colder, with smaller radiative cooling, making it easier to drive a reverse cell. (Rosenfeld and Schoeberl [1986] have calculated a reversed cell for October 1980.) In that case, the minimum would also be related to less wave activity.

The ozone data show two long term trends. At the upper levels in Figure $15 a$ there is a fairly steady downward trend. This is also seen at other latitudes; it may be due to instrument drift for the shorter wavelengths that provide the upper altitude information, or a real effect. We will not comment further on this. At the lower levels, the time mean effects appear to be driven by wave activity, consistent with the interannual variations that are seen. It does not appear impossible that a long-term trend in wave activity could lead to long term ozone changes at high southern latitudes.

These results, then, indicate the dynamical effects play a large role in year-to-year variations of ozone at high latitudes, and perhaps in the long-term trend. They do not preclude a role for chemical effects over a longer period.

Acknowledgments. We thank Byron A. Boville, Guy Brasseur, Matthew H. Hitchman and William J. Randel for their helpful comments on the manuscript, and Mark Schoeberl and Robert Hudson for stimulating discussions. Thanks are also due to Cheryl A. Craig and Daniel Packman for their considerable help in reading and mapping the SBUV data, and Lawrence $V$. Lyjak for assistance with several other calculations. This work was supported in part by National Aeronautics and Space Administration through grant W16215.

\section{REFERENCES}

Angell, J. K., The close relation between Antarctic total-ozone depletion and cooling of the Antarctic low stratosphere, Geophys. Res. Lett., 13, 1240-1243, 1986. 
Baldwin, M. P., H. J. Edmon, and J. R. Holton, A diagnostic study of eddy-mean flow interaction during FGGE SOP-1,J. Atmos. Sci., 42, 1838-1845, 1985

Barnett, J. J., The mean meridional temperature behaviour of the stratosphere from November 1970 to November 1971 derived from measurements by The Selective Chopper Radiometer on Nimbus IV, Q. J. R. Meteorol. Soc., 100, 505-530, 1974.

Chubachi, S., Preliminary result of ozone observations at Syowa station from February 1982 to January 1983, Mem. Nat. Inst. Polar Res., Spec. Iss., 34, 13-19, 1984.

Dunkerton, T., C.-P. Hsu, and M. E. McIntyre, Some Eulerian and Lagrangian Diagnostics for a model stratospheric warming, $J$ Atmos. Sci., 38, 819-843, 1981.

Edmon, H. J., B. J. Hoskins, and M. E. McIntyre, Eliassen-Palm cross sections for the troposphere, J. Atmos. Sci., 37, 2600-2616, 1980a.

Edmon, H. J., B. J. Hoskins, and M. E. McIntyre, Corrigendum, J. Atmos. Sci., 38, 1115, 1980 b.

Farman, J. C., B. G. Gardiner, and J. D. Shanklin, Large losses of total ozone in Antarctica reveal seasonal $\mathrm{ClO}_{x} / \mathrm{NO}_{x}$ interaction, Nature, 35, 207-210, 1985.

Farrara, J. C., and C. R. Mechoso, An observational study of the final warming in the southern hemisphere stratosphere, Geophys. Phys. Lett., 13, 1232-1235, 1986.

Geller, M. A., M.-F. Wu, and M. E. Gelman, Tropospherestratosphere (surface- $55 \mathrm{~km}$ ) monthly winter general circulation statistics for the northern hemisphere Four year averages, J. Atmos. Sci., 40, 1334-1352, 1983

Geller, M. A., M.F. Wu, and M. E. Gelman, Tropospherestratosphere (surface-55 $\mathrm{km}$ ) monthly winter general circulation statistics for the northern hemisphere-Interannual variations, $J$ Atmos. Sci., 4I, 1726-1744, 1984.

Gille, J. C., P. L. Bailey, and J. M. Russell, III, Temperature and composition measurements from the I.r.i.r. and l.i.m.s. experiments on Nimbus 6 and 7, Philos. Trans. R. Soc. London, Ser. A, 296 205-218, 1980.

Hartmann, D. L., The structure of the stratosphere in the southern hemisphere during late winter 1973 as observed by satellite, $J$. Atmos. Sci., 33, 1141-1154, 1976

Hartmann, D. L., and R. R. Garcia, A mechanistic model of ozone transport by planetary waves in the stratosphere, J. Atmos. Sci., 36, 350-364, 1979.

Hartmann, D. L., C. R. Mechoso, and K. Yamazaki, Observations of wave-mean flow interaction in the southern hemisphere, $J$. Atmos. Sci., 4I, 351-362, 1984.

Harwood, R. S., The temperature structure of the southern hemisphere stratosphere, $O . J$. R. Meteorol. Soc., IOI, 75-91, 1975

Hirota, I., T. Hirooka, and M. Shiotani, Upper stratospheric circulations in the two hemispheres observed by satellites, Q.J.R. Me teorol. Soc., 109, 443-454, 1983.

Holton, J. R., The Dynamic Meteorology of the Stratosphere and Mesosphere, Meteorol. Monogr., vol. 37, 218 pp., American Meteorological Society, Boston, Mass., 1975.

Knittel, J., Ein Beitrag zur Klimatologie der Stratosphäre der südhaldkugel, Meteorol. Abh. Berlin, A2, 1976.

Kohri, W. J., LRIR observations of the structure and propagation of the stationary planetary waves in the northern hemisphere during December 1975, cooperative Ph.D. thesis, Drexel Univ. and Natl. Cent. for Atmos. Res., Boulder, Colo., 1981.

Labitzke, K., and J. J. Barnett, Global time and space changes of satellite radiances received from the stratosphere and lower mesosphere, J. Geophys. Res., 78, 483-496, 1973.
Mahlman, J. D., and S. B. Fels, Antarctic ozone decreases: A dynamical cause?, Geophys. Res. Lett., 13, 1316-1319, 1986.

Matsuno, T., A dynamical model of the stratospheric sudden warming, J. Atmos. Sci., 28, 1479-1494, 1971.

McPeters, R. D., R. D. Hudson, P. K. Bhartia, and S. L. Taylor, The vertical ozone distribution in the Antarctic ozone minimum measured by SBUV, Geophys. Res. Lett., 13, 1213-1216, 1986.

Mechoso, C. R., D. L. Hartmann, and J. D. Farrara, Climatology and interannual variability of wave, mean-flow interaction in the southern hemisphere, J. Atmos. Sci., 42, 2189-2206, 1985.

Newman, P. A., The final warming and polar vortex disappearance during the southern hemisphere, Geophys. Res. Lett., 13, 1228-1231, 1986.

Newman, P. A., and M. R. Schoeberl, October Antarctic temperature and total ozone trends from 1979-1985, Geophys. Res. Lett., 13, 1206-1209, 1986

Randel, W. J., The evaluation of winds from geopotential height data in the stratosphere, J. Atmos. Sci., in press, 1987.

Robinson, W. A., The application of the quasi-geostrophic EliassenPalm flux to the analysis of stratospheric data, J. Atmos. Sci., 43, 1017-1023, 1986

Rodgers, C. D., Statistical principles of inversion theory, in Inversion Methods in Atmospheric Remote Sounding, edited by A. Deepak, pp. 117-138, Academic, Orlando, Fla., 1977.

Rosenfeld, J. E., and M. R. Schoeberl, A computation of stratospheric heating rates and diabatic circulation for the Antarctic spring, Geophys. Res. Lett., 13, 1339-1342, 1986.

Sekiguchi, Y., Antarctic ozone change correlated to the stratospheric temperature field, Geophys. Res. Lett., I3, 1202-1205, 1986.

Shiotani, M., and I. Hirota, Planetary wave-mean flow interaction in the stratosphere: A comparison between northern and southern hemispheres, Q. J. R. Meteorol. Soc., $111,309-334,1985$.

Solomon, S., R. R. Garcia, F. S. Rowland, and D. J. Wuebbles, On the depletion of Antarctic ozone, Nature, 32I, 755-758, 1986

Stolarski, R. S., A. J. Krueger, M. R. Schoeberl, R. D. McPeters, P. A Newman, and J. C. Alpert, Nimbus 7 SBUV/TOMS measurements of the springtime Antarctic ozone hole, Nature, 322, 808-811, 1986.

Tung, K.-K., M. K. W. Ko, J. M. Rodriguez, and N. D. Sze, Are Antarctic ozone variations a manifestation of dynamices or chemistry?, Nature, 322, 811-814, 1986.

World Meteorological Organization (WMO), Atmospheric ozone 1985, WMO Rep. 16, Geneva, 1986.

Wu, M.-F., M. A. Geller, J. G. Olson, A. J. Miller, and R. M. Nagatani, Computation of ozone transport using Nimbus 7 solar backscatter ultraviolet and NOAA/National Meteorological Center data, J. Geophys. Res., 90, 5745-5755, 1985.

Yamazaki, K., and C. R. Mechoso, Observations of the final warming in the stratosphere of the southern hemisphere during $1979, J$. Atmos. Sci., 42, 1198-1205, 1985.

J. C. Gille, National Center for Atmospheric Research, P.O. Box 3000, Boulder, CO 80307

M. Shiotani, Geophysical Institute, Kyoto University, Kyoto 606, Japan.
(Received October 24, 1986; revised April 14, 1987 ; accepled April 20, 1987. 